\title{
Perception of smile esthetics by laypeople of different ages
}

\author{
Chompunuch Sriphadungporn and Niramol Chamnannidiadha*
}

\begin{abstract}
Background: Age is a factor affecting smile esthetics. Three variables of smile esthetics associated with the maxillary anterior teeth and age-related changes have recently received considerable attention: (i) the incisal edge position of the maxillary central incisors, (ii) the maxillary gingival display, and (iii) the presence of a black triangle between the maxillary central incisors. The aim of this study was to evaluate the influence of age on smile esthetic perception based on these three variables in a group of Thai laypeople.

Methods: The smiles were constructed from a photograph of a female smile. Smile photographs were altered in various increments using three variables: the incisal edge position of the maxillary incisors, gingival display, and a black triangle between the maxillary central incisors. The photographs were shown to a group of 240 Thai laypeople. The subjects were divided into two groups: a younger group, $15-29$ years old $(n=120)$ and an older group, 36-52 years old $(n=120)$. Each subject was asked to score the attractiveness of each smile separately using a visual analog scale.

Results: Smile attractiveness scores concerning the incisal edge positions of the maxillary central incisors were similar between the two groups. However, upper lip coverage was rated as unattractive by the younger group. A gingival display of 0 and $2 \mathrm{~mm}$ was rated as most attractive by the younger group. Upper lip coverage and gingival display of 0 and $2 \mathrm{~mm}$ were considered attractive by the older group. Excessive gingival display $(6 \mathrm{~mm})$ was scored as unattractive by both groups. A black triangle ranging from 1 to $2.5 \mathrm{~mm}$ between the maxillary central incisors was scored differently between the two groups. The older group was more tolerant of the black triangle size.

Conclusions: Age impacts smile perception based on maxillary gingival display and the presence of a black triangle between the maxillary central incisors, but not of the incisal edge position of the maxillary central incisors. Due to the variation in esthetic perception of each individual, participation between orthodontists and patients for decisionmaking and treatment planning is a crucial process to provide successful results.
\end{abstract}

Keywords: Visual perception, Smile, Esthetics, Age

\section{Background}

Recently, the focus on facial esthetics as an indicator of social value has increased. The smile is an important aspect of facial esthetics. Therefore, many orthodontists are incorporating facial esthetics into their treatment planning to achieve a beautiful and youthful smile $[1,2]$. However, beauty truly is in the eye of the beholder. The patients' personal experience and social environment affect their preference towards smile esthetics more highly than the dentists' or orthodontists' opinion does [3]. In addition, an individual's esthetic evaluation is

\footnotetext{
* Correspondence: niramol.c@chula.ac.th

Chulalongkorn University, 34 Henri Dunant Road, Pathumwan, Bangkok 10330, Thailand
}

considerably impacted by factors such as education level, social status, and cultural differences [3-5]. Mass media, including television, radio, advertising, movies, magazines, and the internet, also play an important role in the perception of beauty in modern culture [6]. The definition of dental beauty differs across populations, regions, countries, and even continents [5, 7]. Dental beauty is also dynamic, with its parameters changing over time [8]. Currently, the interest in esthetic dentistry has increased, resulting in individuals of different ages seeking orthodontic treatment. Age is a factor affecting the perception of smile esthetics [9]. Previous studies [10-15] have evaluated esthetic perception in terms of smiles with a diastema and midline deviation, smile arc, 
missing teeth, buccal corridor, and gummy smile in different age groups. The results of most studies [10-13] suggested that there were dissimilar perceptions in different age ranges due to evolving attitudes, lifestyles, and opinions. The maxillary anterior teeth are a key esthetic component of a smile [16]. Three variables of smile esthetics associated with the maxillary anterior teeth and age-related changes have recently received considerable attention: the incisal edge position of the maxillary central incisors [17-19], the maxillary gingival display [20-23], and the presence of a black triangle between the maxillary central incisors [24-26]. As people grow older, these variables can change and may affect smile esthetics. Orthodontists have become increasingly aware of the soft tissue esthetics resulting from treatment and satisfying the patient's perception of an esthetic outcome [27]. Esthetic treatment planning starts with the position of the maxillary central incisors [28]. The first step in esthetic orthodontic treatment planning is always establishing the vertical position of the maxillary incisors when smiling [29]. The vertical position of the maxillary incisor has great impact on smile esthetics through the smile arc, which been noted by many investigators [14, 29-32]. As a person ages, their smile arc curvature tends to flatten and with worn dentition, a reverse smile arc can develop [33, 34]. Studies have found that the orthodontists' perceptions and preferences in smile esthetics do not always correlate with those of the patients [19, 35]. However, there was also a study showing similar preferences in esthetics between orthodontists and patients [31]. Therefore, having a thorough knowledge in the perception of this variable may guide orthodontists in preparing an appropriate treatment plan.

Another feature contributing to smile esthetics is the gingival display. Evaluating the amount gingival display in the esthetic zone is crucial [29]. The optimal correlation of the upper lip to the maxillary incisors and gingiva on smiling differed significantly between orthodontists and patients. One ideal upper lip position determined by some studies is for the lower margin of the upper lip to align evenly with the gingival margin of the maxillary central incisors [36, 37]. However, other studies found that some degree of maxillary incisor visibility together with some gingival display is more attractive compared with a complete lack of gingival display or partial tooth coverage by the upper lip [16, 38]. Upper lip coverage tends to increase with age due to lip sagging [39], and therefore, the percentage of gummy smiles may be higher among younger age groups and lower among older adults. Studies of laypeople's perspectives found a wide range of acceptable gingival display with a maximum of $4 \mathrm{~mm}$ of the gingival display and maximum of $4.5 \mathrm{~mm}$ of lip coverage, whereas from orthodontists' point of view, the acceptable range was $0-2 \mathrm{~mm}[14,32,38,40,41]$. Based on these findings, it is an important error if orthodontists believe that the patients' esthetic preferences are the same as theirs.

Another parameter affecting the perception of an esthetic smile is the presence of black triangle, which arises from decreased papilla length at the contact point between the central incisors [42], resulting in the embrasure cervical to the interproximal contact not being filled by gingival tissue [43]. Anatomically, this is a minor issue; however, from an esthetic viewpoint, this small space is of great importance, especially in the anterior teeth, because it is quite visible when smiling $[44,45]$. A space between the incisors due to loss of the interdental papilla and bone is more common in adult patients [46], occurring in more than $1 / 3$ of adults [47]. Moreover, this space is also common in post-orthodontic treatment, found in 38 and $42 \%$ of adult [47] and adolescent [42] patients, respectively. Understanding a patient's preference prior to commencing therapy may help in developing an appropriate treatment plan and successful result.

Previous studies [10-15] found disparate results when evaluating the relationship between age and smile perception in various aspects such as smile arc, gingival display, midline diastema, missing teeth, and a black triangle between the maxillary central incisor and buccal corridor. Lacerda-Santos et al. [12] compared the smile attractiveness of the various sized buccal corridors between groups of individuals in different age ranges. Laypeople over 65 years old were found to be less critical when evaluating the different smile images compared with the younger group. In addition, Gerritsen et al. [13] found that Tanzanian subjects over 45 years old were less dissatisfied with missing maxillary teeth compared with those lower than 45 years old. In contrast, Gracco et al. [15] found that there was no significant difference in assessment of the esthetic value of the buccal corridor on smile perception between age groups. Another feature related with smile perception is the black triangle. The presence of a black space between the maxillary central incisors was considered more attractive by the older group compared with the younger group [11]. When assessing gingival display by Mokhtar et al. [10], the older group (over 40 years old) was less tolerant than the younger group. Moreover, the presence of a diastema was more accepted in older group than younger group. In contrast, a study [14] considering the influence of the smile arc in conjunction with gingival display on smile attractiveness found that age had no effect on esthetic perception.

The majority of these studies [10-13] found a relationship between age groups and the perception of a smile. However, the influence of age on smile perception remains unresolved $[10-12,14]$. The null hypothesis in our study was that differences in these variables would be rated as equally attractive by different age groups. 
Therefore, the aim of this study was to evaluate the influence of age on smile esthetic perception, using varying incisal edge positions of the maxillary central incisors, maxillary gingival display, and the presence of a black triangle between the maxillary central incisors.

\section{Methods}

This study was approved by the Human Research Ethics Committee of the Faculty of Dentistry, Chulalongkorn University. Based on the results of a pilot study, a sample size calculation was performed using n4studies (Version 1.4.1) [48]. Using a significance level of alpha $=$ 0.05 and the sample size was calculated to achieve $80 \%$ power. The sample size calculation indicated that 95 subjects were needed in each group.

The subjects were selected by purposive sampling. Twohundred and forty Thai laypeople living in Bangkok, Thailand, were asked to participate in this study. The subjects were categorized into two groups based on their generation: generation Y: $15-29$ years old $(n=120)$ and generation X: $36-52$ years old $(n=120)$, as defined by Strauss and Howe $[49,50]$. Each age group was comprised of $50 \%$ males and females. The participants were recruited from shopping malls, educational institutions, and offices. Dental professionals and dental students were excluded from this study.

\section{Photo album}

The photo album used for evaluation consisted of three photo sets based on three variables: incisal edge position of the maxillary incisors, gingival display, and black triangle. Each set included six different photographs and one randomly selected repeated smile photograph to test reliability. The selected smile was a frontal view of a young adult Thai female. To minimize any distracting variables, other facial structures were excluded from the smile photographs. The smile features in the photographs were digitally altered into 18 photographs using Adobe Photoshop CS6 (Adobe Systems Inc., San Jose, CA). The photographs were manipulated to create a symmetrical image and adjusted using a ruler (present in the photograph) to represent the actual size of the patient's teeth. The modifications were intentionally created to demonstrate a smile esthetic discrepancy. The photographs were grouped into three sets, each representing an altered smile feature in various increments. The alterations were chosen following consultation with clinically experienced orthodontists and adopted from previous studies $[11,19,35,40]$.

Set 1: the incisal edge position of the maxillary central incisors Gingival margins of the central incisors and canines were equal, and the incisal edges of the central incisors were $0.5 \mathrm{~mm}$ inferior to the lateral incisors in the reference image. The incisal edge position of the maxillary central incisors was adjusted incisally or gingivally using $0.5-\mathrm{mm}$ increments, with the line between the gingival margin of the central incisors and canines serving as a reference plane. The maxillary central incisors were moved gingivally and incisally 0.5 and $0.5-2.0 \mathrm{~mm}$, respectively (Table 1 and Fig. 1).

\section{Set 2: gingival display}

The distance between the upper lip and gingival margin of the maxillary incisors was $0 \mathrm{~mm}$ in the reference image. The gingival display was altered using 2-mm increments by decreasing $(-)$ the distance of the gingival margin between the maxillary incisors and upper lip by 2.0 and $4.0 \mathrm{~mm}$ and by increasing $(+)$ the margin by 2.0 , 4.0, and $6.0 \mathrm{~mm}$ (Fig. 2).

\section{Set 3: black triangle between the maxillary central incisors}

Black triangles of different sizes were created between the maxillary central incisors. This resulted in six photographs: the reference image with no black triangles and the other images with increasing sizes of black triangles, using $0.5-\mathrm{mm}$ increments $(0.5,1,1.5,2$, and $2.5 \mathrm{~mm})$ (Fig. 3).

The photographs were printed on photographic paper to create a photo album. The photographs in each set were coded from 1 to 6 . Photograph number 7 was identical to one randomly selected image in the set to assess reliability. The sets of photos were arranged according to set number; however, the photographs displaying the incremental changes were randomly arranged.

\section{Questionnaires}

Questionnaires were distributed to the participants. The participants were asked to score the attractiveness of each smile image separately using a visual analog scale (VAS), graded from least attractive to most attractive. The questionnaire consisted of two parts:

1. Part 1 elicited demographic data of the participant to determine nationality, sex, and age.

2. Part 2 consisted of visual analog scales pages.

A 10-cm VAS was used for individual ratings. The left end (at zero) of the scale was labeled as least attractive and the right end (at the $10-\mathrm{cm}$ range) was labeled as most attractive. Each participant was asked to mark along the VAS according to their perception of dental esthetics. Each mark on the VAS was measured with a caliper and recorded. The participants were requested to not directly compare the images. The time to evaluate each image was limited to $1 \mathrm{~min}$. 
Table 1 Characteristics of the smiles used in this study

\begin{tabular}{lll}
\hline Adjusted vertical positions of the maxillary central incisors & Gingival margins of the maxillary central incisors & Central to lateral incisor edge level \\
\hline (1) $0.5 \mathrm{~mm}$ intruded & $0.5 \mathrm{~mm}$ above the canines & $0 \mathrm{~mm}$ \\
(2) $0 \mathrm{~mm}$ unaltered & Equal with the canines & $0.5 \mathrm{~mm}$ \\
(3) $0.5 \mathrm{~mm}$ extruded & $0.5 \mathrm{~mm}$ below the canines & $1.0 \mathrm{~mm}$ \\
(4) $1.0 \mathrm{~mm}$ extruded & $1.0 \mathrm{~mm}$ below the canines & $1.5 \mathrm{~mm}$ \\
(5) $1.5 \mathrm{~mm}$ extruded & $1.5 \mathrm{~mm}$ below the canines & $2.0 \mathrm{~mm}$ \\
(6) $2.0 \mathrm{~mm}$ extruded & $2.0 \mathrm{~mm}$ below the canines & $2.5 \mathrm{~mm}$ \\
\hline
\end{tabular}

\section{Statistical analysis}

The data was found to be not normally distributed using the Kolmogorov-Smirnov test. The differences in scores between photographs within a given set were evaluated using Friedman's test and the Wilcoxon signed-rank test for pair-wise comparisons. The differences in scoring between age groups were assessed using the MannWhitney $U$ test. All tests were performed at a 0.05 significance level. To assess intraparticipant agreement, the intraclass correlation coefficient (ICC) was used to compare image scores.

\section{Results}

The mean ages in the 15-29 year-old and 36-52 yearold groups were 22 and 43, respectively. The intraclass correlation coefficients for both participant groups were equal to or higher than 0.79 , which indicated good reliability [51].

There was no significant difference in esthetic scores between the male and female participants in either age group. Therefore, the data for the male and female participants in each age group were pooled and used for further analysis.

The incisal edge position of the maxillary central incisors There was no significant difference in scoring between the images either within or between age groups (Table 2).

\section{Gingival display}

In the younger group, -4 and $+6 \mathrm{~mm}$ gingival displays were rated as the least attractive, whereas 0 and $+2 \mathrm{~mm}$ gingival displays were perceived as the most attractive (Table 3). In the older group, deviations from -4 to $+2 \mathrm{~mm}$ had no significant effect on scores, while a +6 $\mathrm{mm}$ gingival display was perceived as the least attractive. Comparison between age groups showed a significant difference for -4 to $+2 \mathrm{~mm}$ gingival displays $(p<0.05)$. The younger age group gave lower ratings for gingival displays of -4 and $-2 \mathrm{~mm}$ compared with the older group. In contrast, 0 and $+2 \mathrm{~mm}$ gingival displays were given higher ratings in the younger group compared with those in the older group. However, excessive gingival display $(+6 \mathrm{~mm})$ was rated as the most unattractive in both groups.

\section{Black triangle between the maxillary central incisors}

Evaluation of a black triangle tended to result in a lower score as the size of the space increased in both age groups; however, the older group gave higher scores compared with the younger group at the same space size (Table 4). The images without a black triangle were rated as the most attractive, whereas the lowest scores were seen for the 2- and $2.5-\mathrm{mm}$ black triangle images. Compared between age groups, there were no significant differences in scores of the absence of a black triangle and a small black triangle $(0.5 \mathrm{~mm})$. Increasing the size of the black triangles from 1 to $2.5 \mathrm{~mm}$ resulted in significant differences between the age groups; with the
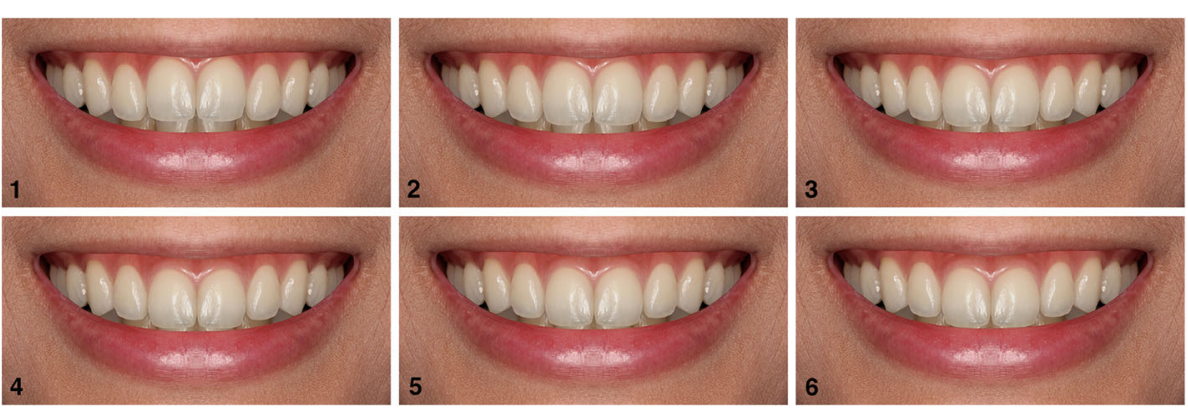

Fig. 1 Altered incisal edge position of the maxillary central incisors in 0.5-mm increments. $10.5 \mathrm{~mm}$ intruded; $\mathbf{2} 0 \mathrm{~mm}$ extruded; $\mathbf{3} 0.5 \mathrm{~mm}$ extruded; $41.0 \mathrm{~mm}$ extruded; $51.5 \mathrm{~mm}$ extruded; and $\mathbf{6} 2.0 \mathrm{~mm}$ extruded 

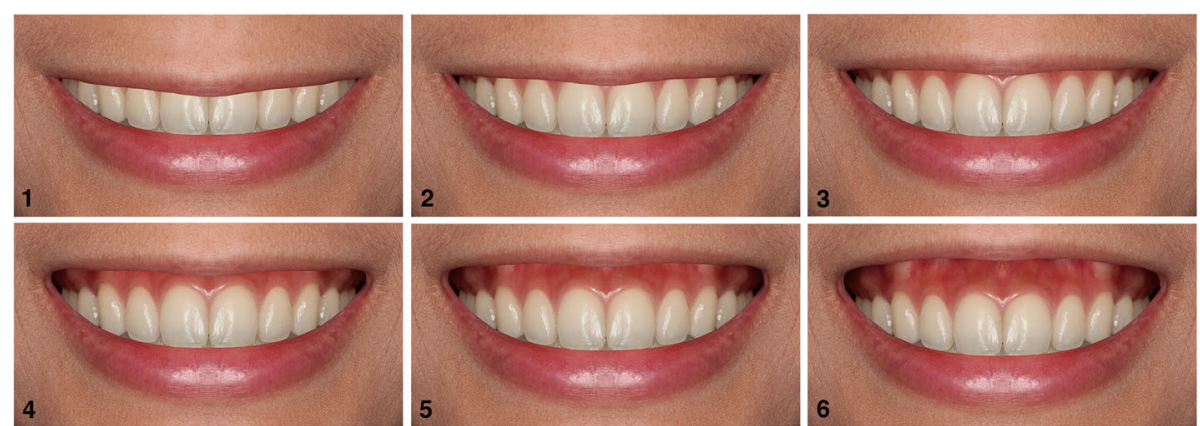

Fig. 2 Altered gingival display in 2.0-mm increments. $\mathbf{1}-4 \mathrm{~mm} ; \mathbf{2}-2.0 \mathrm{~mm} ; \mathbf{3} 0 \mathrm{~mm} ; \mathbf{4}+2.0 \mathrm{~mm} ; \mathbf{5}+4.0 \mathrm{~mm}$; and $\mathbf{6}+6 \mathrm{~mm}$

older group being more tolerant of the size of black triangles $(p<0.05)$.

\section{Discussion}

This study evaluated the differences in smile esthetic perception between a younger and older age group. Our results indicated the presence of differences in perception between these groups. Based on these findings, the null hypothesis was rejected. Our study is the first to demonstrate the perception of the vertical position of the maxillary central incisors when smiling by different aged laypeople. We found no statistical difference in the participants' preference for vertical incisal edge position. Comparing the two age groups, age did not affect the perception of smiles when varying this variable. Both groups shared similar preferences when evaluating minor discrepancies in incisal edge positions of the maxillary central incisors at any level. This result was inconsistent with the study of Machado et al. [19], who showed a preference for having a different vertical edge position between the central and lateral incisors among college students. The most attractive smiles for laypeople were smiles with a 1-2-mm central to lateral incisor edge level difference, whereas a study performed by King et al. [52] noted this step was only $0.6 \mathrm{~mm}$. These differences with our findings are probably because laypeople are not as sensitive to such minor discrepancies as orthodontists, as shown by Machado et al. [19]. This study found that laypeople were more tolerant of minor discrepancies by ranking altered smiles with higher scores. King et al. [52] also stated that orthodontists had a smaller range of acceptable altered maxillary central to lateral incisor edge levels compared with laypeople. Furthermore, in our study, it is possible that some participants liked both flat and consonant smiles.

The results of our study imply that minor discrepancies between maxillary central and lateral incisor edges have no influence on laypeople's perception. This is probably because the discrepancies were symmetrical, as asymmetrical discrepancies strongly affected their perception in a previous study $[35,53]$. Even a slight incisal edge discrepancy of $0.5 \mathrm{~mm}$ between the maxillary central incisors was considered as unattractive by laypeople and orthodontists [35]. This may indicate that as long as the maxillary central incisors are symmetrical, minor vertical position differences between the maxillary central and lateral incisors do not always need to be treated. Thus, orthodontists should not make these decisions alone; the patients should also participate to establish an appropriate treatment plan, as many studies [19, 35, $38,40,41,53]$ concluded that orthodontists are more observant in detecting deviations from ideal positions. Thus, their decisions might be based on excessive concern and lead to unnecessary treatment.
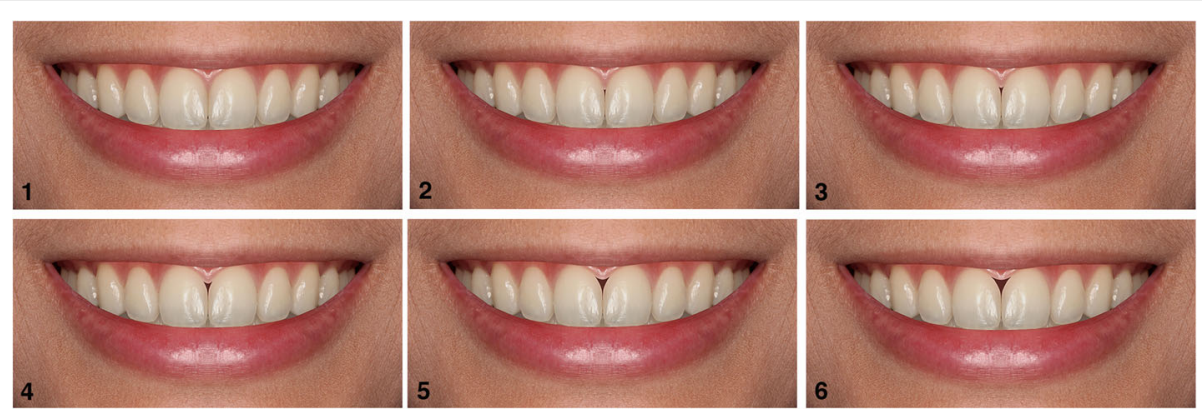

Fig. $\mathbf{3}$ Altered black triangles between the maxillary central incisors in 0.5-increments. $\mathbf{1}$ no black triangle; $\mathbf{2} 0.5 \mathrm{~mm} ; \mathbf{3} 1.0 \mathrm{~mm} ; \mathbf{4} 1.5 \mathrm{~mm}$; $\mathbf{5} 2.0 \mathrm{~mm}$; and $\mathbf{6} 2.5 \mathrm{~mm}$ 
Table 2 Photograph ratings by age group of altered incisal edge positions of the maxillary central incisors

\begin{tabular}{|c|c|c|c|c|c|c|c|}
\hline \multirow{3}{*}{$\begin{array}{l}\text { Central-lateral } \\
\text { incisor edge } \\
\text { level (mm) }\end{array}$} & \multicolumn{6}{|c|}{ Age groups } & \multirow[t]{3}{*}{$p$ value } \\
\hline & \multicolumn{3}{|c|}{ 15-29 years old } & \multicolumn{3}{|c|}{$36-52$ years old } & \\
\hline & $\overline{\text { Mean }}$ & SD & Result $^{a}$ & $\overline{\text { Mean }}$ & SD & Result $^{a}$ & \\
\hline Image $1(0)$ & 6.80 & 1.88 & A & 6.69 & 1.67 & A & $0.454 \mathrm{NS}$ \\
\hline Image $2(0.5)$ & 6.90 & 1.57 & A & 6.96 & 1.65 & A & $0.322 \mathrm{NS}$ \\
\hline Image 3 (1) & 6.98 & 1.80 & A & 6.77 & 1.63 & A & 0.192 NS \\
\hline mage 4 (1.5) & 7.04 & 1.72 & A & 6.78 & 1.54 & A & 0.132 NS \\
\hline mage 5 (2) & 6.74 & 1.85 & A & 6.79 & 1.87 & A & 0.964 NS \\
\hline hage 6 (2.5) & 6.89 & 1.92 & A & 6.83 & 1.76 & A & 0.549 NS \\
\hline
\end{tabular}

NS not significant

${ }^{\mathrm{a}}$ In each age group, scores of the images with the same letter were not significantly different

When considering the maxillary gingival display, a disagreement in smile attractiveness was found between age groups. The younger group rated a gingival display of $0-2 \mathrm{~mm}$ as the most attractive. This finding corresponds with the study of Hunt et al. [54] and Geron et al. [55], with the latter stating that some gingival display is often esthetically appealing because it corresponds with a more youthful appearance.

The tendency in the younger group was that increased upper lip coverage of the teeth resulted in a more unattractive smile. This perception was probably caused by the assumption that upper lip coverage is a sign of aging [39]. In the older group, upper lip coverage was preferred, as this is prone to occur at their age. These different esthetic perceptions might be explained by the form concept [56], which states that the more an individual experiences certain smile appearances, the more likely they are to perceive it as being normal. Another possible reason was that adults' teeth tend to have more defects such as black triangles, spacing, crowding, or restorations. Excessive tooth exposure may thus reveal what they would rather conceal. These findings for the younger group are

Table 3 Photograph ratings by age group of altered gingival display

\begin{tabular}{|c|c|c|c|c|c|c|c|}
\hline \multirow{3}{*}{$\begin{array}{l}\text { Gingival } \\
\text { display } \\
(\mathrm{mm})\end{array}$} & \multicolumn{6}{|c|}{ Age groups } & \multirow[t]{3}{*}{$p$ value } \\
\hline & \multicolumn{3}{|c|}{ 15-29 years old } & \multicolumn{3}{|c|}{ 36-52 years old } & \\
\hline & Mean & SD & $\overline{\text { Result }^{a}}$ & Mean & SD & Result $^{a}$ & \\
\hline Image $1(-4)$ & 2.93 & 1.67 & A & 5.90 & 1.96 & A & $0.000^{* *}$ \\
\hline Image $2(-2)$ & 3.86 & 1.38 & B & 5.89 & 1.80 & A & $0.000^{* *}$ \\
\hline Image $3(0)$ & 6.88 & 1.42 & C & 5.81 & 1.61 & A & $0.000^{* *}$ \\
\hline Image $4(+2)$ & 7.40 & 1.36 & C & 5.78 & 1.59 & A & $0.000^{* *}$ \\
\hline Image $5(+4)$ & 4.74 & 1.71 & $B$ & 4.64 & 1.46 & $B$ & $0.532 \mathrm{NS}$ \\
\hline Image $6(+6)$ & 2.98 & 1.96 & $A$ & 2.94 & 1.49 & C & $0.882 \mathrm{NS}$ \\
\hline
\end{tabular}

Table 4 Photograph ratings by age group of altered black triangles

\begin{tabular}{|c|c|c|c|c|c|c|c|}
\hline \multirow{3}{*}{$\begin{array}{l}\text { Black } \\
\text { triangle } \\
(\mathrm{mm})\end{array}$} & \multicolumn{6}{|c|}{ Age groups } & \multirow[t]{3}{*}{$p$ value } \\
\hline & \multicolumn{3}{|c|}{$15-29$ years old } & \multicolumn{3}{|c|}{$36-52$ years old } & \\
\hline & $\overline{\text { Mean }}$ & SD & $\overline{\text { Result }^{a}}$ & $\overline{\text { Mean }}$ & SD & $\overline{\text { Result }^{a}}$ & \\
\hline Image $1(0)$ & 7.05 & 2.23 & A & 7.24 & 1.79 & $A$ & $0.805 \mathrm{NS}$ \\
\hline mage $2(0.5)$ & 5.53 & 2.46 & B & 6.13 & 1.86 & B & 0.058 NS \\
\hline Image 3 (1) & 4.59 & 2.22 & C & 5.36 & 1.89 & C & $0.002^{* *}$ \\
\hline mage 4 (1.5) & 4.28 & 2.22 & C & 5.02 & 2.00 & C & $0.002^{* *}$ \\
\hline Image 5 (2) & 3.38 & 2.25 & $\mathrm{D}$ & 4.32 & 2.00 & D & $0.000^{* *}$ \\
\hline Image 6 (2.5) & 2.98 & 2.26 & D & 3.87 & 2.07 & $\mathrm{D}$ & $0.001^{* *}$ \\
\hline
\end{tabular}

NS not significant

${ }^{* *}$ Statistical differences between age groups $(p<0.05)$

an each age group, scores of the images with the same letter were not significantly different

inconsistent with those of Ioi et al. [5] who reported that young laypeople preferred a smile with tooth coverage by the upper lip. These findings might be related to ethnic and social differences in smile preference.

Although gummy smiles may be more common among younger age groups [57] and less common among older adults [58], it is noteworthy that excessive gingival display $(6 \mathrm{~mm})$ was not tolerated by either age group. Increasing gingival display from 4 to $6 \mathrm{~mm}$ significantly impacted attractiveness, with rating scores decreasing by $37 \%$. These results coincided with those of Kokich et al. [40] and Ker et al. [7], which noted that laypeople were tolerant of a gummy smile up to $4 \mathrm{~mm}$.

Ioi at al. [5] reported that both Asian adolescences and adults showed a threshold of acceptability for upper incisor coverage of $0-5 \mathrm{~mm}$ in males and $0-2 \mathrm{~mm}$ in females. In contrast, our study found that adults accepted upper lip coverage as well as a gummy smile of up to $4 \mathrm{~mm}$. In contrast, adolescents and young adults rated upper lip coverage as unattractive at any level. The perception of a pleasing smile remains individually subjective and culturally dependent.

Multiple [16, 36, 37, 54] suggest that the ideal upper lip position when smiling should align evenly or deviate up to $2 \mathrm{~mm}$ from the gingival margin of the upper incisors. Thus, orthodontists tend to treat patients from a more academic perspective rather than a subjective one. Studies have shown that orthodontists are more sensitive to a gummy smile compared with laypeople [14, 40,59]. To ensure patient satisfaction with treatment results, making a joint decision between the orthodontist and the patient before the start of the treatment is crucial.

The results of both groups concerning the esthetic effect of black triangles between the maxillary central incisors were similar, i.e., the larger the black triangle, the lower the images were rated. Thus, it is not surprising that in both groups, the absence of a black triangle was considered the most pleasing. However, the presence of a 
very small space $(0.5 \mathrm{~mm})$ was likely acceptable because it is too small to affect the perception of laypeople at any age.

Pithon et al. [11] found no significant difference between black space esthetic scores in groups 15-19 and 35-44 years old. However, in our study, the score of images presenting a $1-2.5$-mm black triangle was significantly different between age groups. The older group gave higher scores for all images. These findings indicate that the older group was more tolerant of having a black triangle compared with the younger group. This is probably because black triangles are more common in the adult population, as aging leads to a reduction in interdental papilla height [60]. Thus, older individuals are likely to be more tolerant of this appearance.

We assumed that esthetic scores ranging from 0 to 5 denoted unattractive smiles and scores higher than 5 denoted attractive smiles. Based on this assumption, a $0.5-\mathrm{mm}$ black triangle represented the threshold of acceptability in the younger group, whereas in the older group, $1.5 \mathrm{~mm}$ was the limit of acceptability. The presence of $2-2.5-\mathrm{mm}$ black triangles resulted in the lowest scores in both groups. These results indicated that the participants in our study were slightly more sensitive to black triangles compared with laypeople in the study of Kokich et al. [40], who found that laypeople could detect a 3-mm open gingival embrasure. This difference may reflect that esthetic perception gradually changes over time. However, the patient must be informed prior to treatment of the possibility of this space being created at the end of orthodontic treatment, and the orthodontist should avoid creating this defect. To avoid unnecessary treatment, small discrepancies could be left in some cases, particularly in older patients.

In addition to the presence of a black triangle between the upper central incisors affecting the smile perception, black triangles can be found between other anterior teeth, which also might affect the esthetics. A comparison of these variables is suggested in future studies.

\section{Conclusions}

Age has an impact on the perception of smile esthetics in terms of maxillary gingival display and the presence of a black triangle between the maxillary central incisors, but not of the incisal edge position of the maxillary central incisors. An ideal smile based on academic considerations may not be perceived as the most attractive by laypeople. Due to the variation in esthetic perception by each person, participation between orthodontists and patients for decision-making and treatment planning is crucial to generate successful results.

\section{Abbreviations}

ANOVA: Analysis of variance; ICC: Intraclass correlation coefficient; VAS: Visual analog scale

\section{Acknowledgements}

The authors are grateful to Prof. Vincent Everts, Dr. Kevin Tompkins and Ruben Pauwels for their valuable comments on the manuscript. The study was supported by a Faculty Research Grant (DRF 59013), Faculty of Dentistry, Chulalongkorn University, for 2015 research project.

\section{Funding}

The study was supported by a Faculty Research Grant (DRF 59013), Faculty of Dentistry, Chulalongkorn University.

\section{Availability of data and materials}

Data will not be shared due to the use of data in the future research closely related to the original project.

\section{Competing interests}

The authors declare that they have no competing interests.

\section{Consent for publication}

Not applicable.

\section{Authors' contributions}

$\mathrm{CH}$ was responsible for the literature search, photo albums, and questionnaire construction, data collection, data analysis, data interpretation, and drafting the manuscript. NC conceived the idea for the study, participated in its design and coordination, and provided the feedback on the revisions to the manuscript. Both authors read and approved the final manuscript.

\section{Ethics approval and consent to participate}

The study protocol was approved by the Human Research Ethics Committee of the Faculty of Dentistry, Chulalongkorn University (HREC-DCU 2015-094).

Received: 19 October 2016 Accepted: 27 February 2017

Published online: 20 March 2017

\section{References}

1. Proffit WR, Sarver DM, Ackerman JL. Diagnosis and treatment planning. In: Proffit WR, Fields HW, Sarver DM, editors. Contemporary orthodontics. 4th ed. St. Louis: Mosby Elsevier; 2007. p. 167-233.

2. Kiyak HA. Does orthodontic treatment affect patients' quality of life? J Dent Educ. 2008;72(8):886-94.

3. Flores-Mir C, Silva E, Barriga MI, Lagravere MO, Major PW. Lay person's perception of smile aesthetics in dental and facial views. J Orthod. 2004;31(3):204-9.

4. McLeod C, Fields HW, Hechter F, Wiltshire W, Rody W, Christensen J. Esthetics and smile characteristics evaluated by laypersons. Angle Orthod. 2011;81(2):198-205.

5. Ioi H, Kang S, Shimomura T, Kim SS, Park SB, Son WS, et al. Effects of vertical positions of anterior teeth on smile esthetics in Japanese and Korean orthodontists and orthodontic patients. J Esthet Restor Dent. 2013;25(4):274-82.

6. Russello $\mathrm{S}$. The impact of media exposure on self-esteem and body satisfaction in men and women. J Interdisciplinary Undergrad Res. 2013;1(1):1-12.

7. Ker AJ, Chan R, Fields HW, Beck M, Rosenstiel S. Esthetics and smile characteristics from the layperson's perspective: a computer-based survey study. J Am Dent Assoc. 2008;139(10):1318-27.

8. Patnaik WG, Singla R, Bala S. Anatomy of 'A beautiful face and smile'. J Anat Soc India. 2003:52:74-80.

9. Tüzgiray YB, Kaya B. Factors affecting smile esthetics. Turk J Orthod. 2013;26(1):58-64.

10. Mokhtar HA, Abuljadayel LW, Al-Ali RM, Yousef M. The perception of smile attractiveness among Saudi population. Clin Cosmet Investig Dent. 2015;7:17-23.

11. Pithon MM, Bastos GW, Miranda NS, Sampaio T, Ribeiro TP, Nascimento LE, et al. Esthetic perception of black spaces between maxillary central incisors by different age groups. Am J Orthod Dentofacial Orthop. 2013;143(3):371-5.

12. Lacerda-Santos R, Pereira TB, Pithon MM. Esthetic perception of the buccal corridor in different facial types by laypersons of different ages. Biosci J. 2015;31(4):1283-90. 
13. Gerritsen AE, Sarita P, Witter DJ, Kreulen CM, Mulder J, Creugers NH. Esthetic perception of missing teeth among a group of Tanzanian adults. Int J Prosthodont. 2008;21(2):169-73.

14. Kaya B, Uyar R. Influence on smile attractiveness of the smile arc in conjunction with gingival display. Am J Orthod Dentofacial Orthop. 2013;144(4):541-7.

15. Gracco A, Cozzani M, D'Elia L, Manfrini M, Peverada C, Siciliani G. The smile buccal corridors: aesthetic value for dentists and laypersons. Prog Orthod. 2006;7(1):56-65

16. Sarver DM. The importance of incisor positioning in the esthetic smile: the smile arc. Am J Orthod Dentofacial Orthop. 2001;120(2):98-111.

17. Chou JC, Nelson A, Katwal D, Elathamna EN, Durski MT. Effect of smile index and incisal edge position on perception of attractiveness in different age groups. J Oral Rehabil. 2016;43(11):855-62

18. Wolfart S, Lawrenz B, Schley JS, Kern M, Springer I. Composite images of upper front teeth: judgment of attractiveness and gender-specific correlation. J Esthet Restor Dent. 2014;26(6):394-402.

19. Machado AW, McComb RW, Moon W, Gandini Jr LG. Influence of the vertical position of maxillary central incisors on the perception of smile esthetics among orthodontists and laypersons. J Esthet Restor Dent. 2013;25(6):392-401.

20. Narayanan M, Laju S, Erali SM, Erali SM, Fathima AZ, Gopinath PV. Gummy smile correction with diode laser: two case reports. J Int Oral Health. 2015;7 Suppl 2:89-91.

21. Pandey V. Correction of gummy smiles with botulinum toxin: case report and review. J Adv Med Dent Scie Res. 2014;2(3):137-41.

22. Espinoza-Barco K, Ríos-Villasis K, Liñán-Durán C. Influence of buccal corridor and gingival display in the perception esthetic of the smile. Rev Estomatol Herediana. 2015;25(2):133-44

23. Taki AA, Khalesi M, Shagmani M, Yahia I, Kaddah FA. Perceptions of altered smile esthetics: a comparative evaluation in orthodontists, dentists, and laypersons. Int J Dent. 2016;2016:1-11.

24. Ahmad I. Anterior dental aesthetics: gingival perspective. Br Dent J. 2005:199(4):195-202

25. Cunliffe J, Pretty I. Patients' ranking of interdental "black triangles" against other common aesthetic problems. Eur J Prosthodont Restor Dent. 2009;17(4):177-81.

26. Al Zarea BK, Sghaireen MG, Alomari WM, Bheran $H$, Taher I. Black triangles causes and management: a review of literature. Br J Appl Sci Technol. 2015;6(1):1-7.

27. Sarver DM, Ackerman JL. Orthodontics about face: the re-emergence of the esthetic paradigm. Am J Orthod Dentofacial Orthop. 2000;117(5):575-6.

28. Lombardi RE. The principles of visual perception and their clinical application to denture esthetics. J Prosthet Dent. 1973;29(4):358-82.

29. Machado AW. 10 commandments of smile esthetics. Dental Press J Orthod. 2014;19(4):136-57.

30. Rodrigues Cde D, Magnani R, Machado MS, Oliveira OB. The perception of smile attractiveness. Angle Orthod. 2009;79(4):634-9.

31. Krishnan V, Daniel ST, Lazar D, Asok A. Characterization of posed smile by using visual analog scale, smile arc, buccal corridor measures, and modified smile index. Am J Orthod Dentofacial Orthop. 2008;133(4):515-23.

32. Springer NC, Chang C, Fields HW, Beck FM, Firestone AR, Rosenstiel S, et al. Smile esthetics from the layperson's perspective. Am J Orthod Dentofacial Orthop. 2011;139(1):e91-101.

33. Sabri R. The eight components of a balanced smile. J Clin Orthod. 2005;39(3):155-67.

34. Banerji S, Mehta S. Patient examination and assessment. In: Wilson N, editor. Principles and practice of esthetic dentistry. 1st ed. China: Mosby; 2015. p. 75.

35. Machado AW, Moon W, Gandini Jr LG. Influence of maxillary incisor edge asymmetries on the perception of smile esthetics among orthodontists and laypersons. Am J Orthod Dentofacial Orthop. 2013;143(5):658-64.

36. Mackley RJ. An evaluation of smiles before and after orthodontic treatment. Angle Orthod. 1993:63(3):183-9.

37. Hulsey CM. An esthetic evaluation of lip-teeth relationships present in the smile. Am J Orthod. 1970;57(2):132-44.

38. Kokich VO, Kokich VG, Kiyak HA. Perceptions of dental professionals and laypersons to altered dental esthetics: asymmetric and symmetric situations. Am J Orthod Dentofacial Orthop. 2006;130(2):141-51.

39. Dong JK, Jin TH, Cho HW, Oh SC. The esthetics of the smile: a review of some recent studies. Int J Prosthodont. 1999;12(1):9-19.
40. Kokich Jr VO, Kiyak HA, Shapiro PA. Comparing the perception of dentists and lay people to altered dental esthetics. J Esthet Dent. 1999;11(6):311-24.

41. Kumar S, Gandhi S, Valiathan A. Perception of smile esthetics among Indian dental professionals and laypersons. Indian J Dent Res. 2012;23(2):295.

42. Burke S, Burch JG, Tetz JA. Incidence and size of pretreatment overlap and posttreatment gingival embrasure space between maxillary central incisors. Am J Orthod Dentofacial Orthop. 1994;105(5):506-11.

43. Belser UC, Grutter L, Vailati F, Bornstein MM, Weber HP, Buser D. Outcome evaluation of early placed maxillary anterior single-tooth implants using objective esthetic criteria: a cross-sectional, retrospective study in 45 patients with a 2- to 4-year follow-up using pink and white esthetic scores. J Periodontol. 2009;80(1):140-51.

44. Hochman MN, Chu SJ, Tarnow DP. Maxillary anterior papilla display during smiling: a clinical study of the interdental smile line. Int J Periodontics Restorative Dent. 2012;32(4):375-83.

45. Hu X, Nahles S, Nelson CA, Lin Y, Nelson K. Analysis of soft tissue display during enjoyment smiling: part 1-Caucasians. Int J Periodontics Restorative Dent. 2013;33(1):e9-15.

46. Tarnow DP, Magner AW, Fletcher P. The effect of the distance from the contact point to the crest of bone on the presence or absence of the interproximal dental papilla. J Periodontol. 1992;63(12):995-6.

47. Kurth JR, Kokich VG. Open gingival embrasures after orthodontic treatment in adults: prevalence and etiology. Am J Orthod Dentofacial Orthop. 2001;120(2):116-23.

48. Ngamjarus C, Chongsuvivatwong V, McNeil E. n4Studies: sample size calculation for an epidemiological study on a smart device. Siriraj Med J. 2016;68(3):160-70

49. Howe N, Strauss W. The beginning of history. In: Howe N, Strauss W, editors. Generations: the history of America's future, 1584 to 2069. New York: Morrow; 1991. p. 425-8.

50. Howe N, Strauss W. From babies on board to power teens. In: Howe N, Strauss W, editors. Millennials rising: the next great generation. New York: Vintage Books; 2000. p. 31-58.

51. Landis JR, Koch GG. The measurement of observer agreement for categorical data. Biometrics. 1977:33(1):159-74.

52. King KL, Evans CA, Viana G, BeGole E, Obrez A. Preferences for vertical position of the maxillary lateral incisors. World J Orthod. 2008:9(2):147-54.

53. Rosa M, Olimpo A, Fastuca R, Caprioglio A. Perceptions of dental professionals and laypeople to altered dental esthetics in cases with congenitally missing maxillary lateral incisors. Prog Orthod. 2013;14:1-7.

54. Hunt $O$, Johnston C, Hepper P, Burden D, Stevenson M. The influence of maxillary gingival exposure on dental attractiveness ratings. Eur J Orthod. 2002:24(2):199-204.

55. Geron S, Atalia W. Influence of sex on the perception of oral and smile esthetics with different gingival display and incisal plane inclination. Angle Orthod. 2005:75(5):778-84.

56. Peck H, Peck S. A concept of facial esthetics. Angle Orthod. 1970;40(4):284-318

57. Peck S, Peck L, Kataja M. Some vertical lineaments of lip position. Am J Orthod Dentofacial Orthop. 1992;101(6):519-24.

58. Vig RG, Brundo GC. The kinetics of anterior tooth display. J Prosthet Dent. 1978;39(5):502-4.

59. Talic N, Alomar S, Almaidhan A. Perception of Saudi dentists and lay people to altered smile esthetics. Saudi Dent J. 2013·25(1):13-21.

60. Sharma AA, Park JH. Esthetic considerations in interdental papilla: remediation and regeneration. J Esthet Restor Dent. 2010;22(1):18-28. 